\title{
Lionel Obadia, La marchandisation de Dieu.
} L'économie religieuse

CNRS Éditions, coll. « Philosophie et histoire des idées », 2013, 256 p.

Isabelle Jonveaux

\section{CpenEdition}

\section{Journals}

Édition électronique

URL : http://journals.openedition.org/assr/26524

DOI : $10.4000 /$ assr. 26524

ISSN : $1777-5825$

Éditeur

Éditions de l'EHESS

Édition imprimée

Date de publication : 31 décembre 2014

Pagination : 265

ISBN : 978-2-7132-2467-6

ISSN : 0335-5985

Référence électronique

Isabelle Jonveaux, «Lionel Obadia, La marchandisation de Dieu. L'économie religieuse », Archives de sciences sociales des religions [En ligne], 168 | 2014, mis en ligne le 18 mai 2015, consulté le 22 septembre 2020. URL : http://journals.openedition.org/assr/26524 ; DOI : https://doi.org/10.4000/ assr.26524

Ce document a été généré automatiquement le 22 septembre 2020.

(c) Archives de sciences sociales des religions 


\section{Lionel Obadia, La marchandisation de Dieu. L'économie religieuse}

CNRS Éditions, coll. «Philosophie et histoire des idées », 2013, 256 p.

Isabelle Jonveaux

\section{RÉFÉRENCE}

Lionel Obadia, La marchandisation de Dieu. L'économie religieuse, CNRS Éditions, coll. «Philosophie et histoire des idées », 2013, 256 p. 
1 Le présent ouvrage de Lionel Obadia est dense et complet. Il se présente comme un bon résumé des questions unissant les deux sphères souvent considérées comme antithétiques et conflictuelles que sont l'économie et la religion, en faisant aussi état des travaux sur cette question. Depuis les ouvrages fondateurs de Max Weber, on retient un désenchantement à l'œuvre entre économie et religion qui consomme un divorce profond entre ces deux sphères, mais aussi paradoxalement, la possibilité pour des formes extrêmes de religiosité comme l'ascèse de conduire à une plus grande performance économique. Mais les relations entre économie et religion ne se limitent pas à ces tensions et affinités électives et développent au contraire de multiples recompositions pour que chacune des deux sphères puisse accepter l'autre.

2 Mais qu'entend exactement Lionel Obadia par le vocable d'« économie religieuse ", sous-titre de l'ouvrage? Une définition se trouve à la page 56: "Par économie religieuse, il faut entendre cette démarche de compréhension et d'intelligibilité du religieux qui suppose d'en faire une lecture au prisme de l'économie scientifique et en particulier l'économie politique ». Ce type d'économie est en effet, comme le souligne Iannaccone, l'un des spécialistes de ce champ, à distinguer de l'«économie de la religion» qui "représente pour lui l'économie (en pratique) ou la théorie et les actes économiques tels qu'ils sont promus par les acteurs confessionnels » (p.67). Le champ de l'économie religieuse, inauguré sous cette forme dans les années 1980 se propose donc d'analyser la religion avec des outils venant de l'économie. Ainsi parle-t-on de "marché du religieux», de " consumérisme spirituel» ou encore de « monopole», mais ces techniques font aussi écho à des évolutions internes du champ religieux lui-même. En effet, les religions empruntent de plus en plus des pratiques économiques issues du management, $d u$ business ou du marketing. Mais ces pratiques ne sont pas sans poser le problème d'une potentielle aliénation $\mathrm{du}$ message religieux par ces nouveaux vecteurs de communication. L'économisation du religieux n'est pas sans risque concernant une éventuelle « déperdition symbolique de la religion » (p. 201). Les institutions religieuses peuvent être dans ce cas réduites à des « entrepreneurs du sacré » (A. Greeley, 1989).

3 Mais l'auteur ne demeure pas dans une attitude acritique vis-à-vis des analyses économiques de la religion, dont il remet en question la pertinence et met en lumière le risque d'un «vertige de l'analogie » qui se trouve finalement déconnecté de la réalité. Ainsi que le souligne l'auteur, le fait que les religions fonctionnent comme des « quasisystèmes économiques» (p.133) n'est cependant pas nouveau. Au contraire, «la relation clientéliste au surnaturel n'est en aucun cas moderne par définition » (p. 99). La relation entre le magicien et son client est en effet construite sur le modèle 
économique, ainsi que le montre Weber dans sa typologie bien connue des figures religieuses. Les "biens de salut » ont souvent dans l'histoire été monnayés, la pratique des indulgences dans le christianisme du Moyen Âge en est un exemple parfait. C'est pour cette raison, affirme Lionel Obadia, que l'on doit faire "une approche de l'économie religieuse par son historicité » (p.103) sans attribuer une nouveauté à des faits plus que millénaires et éviter ainsi les fausses corrélations. Il existe en effet différents types de biens religieux rituels, magiques ou de consommation qui portent chacun un niveau différent de symbolique. L'économisation de la religion, c'est aussi l'avènement toujours plus important de "produits dérivés». Développement de l'industrie du tourisme dans les lieux religieux avec offres de voyages organisés et de complexes hôteliers, objets en tout genre allant du réveil avec l'Ave Maria à l'appel électronique du muezzin, le religieux se vend bien et fait l'objet d'une commercialisation toujours réinventée. Mais le plus intéressant est la manière dont ces acteurs économiques essaient de «faire fusionner l'économique et le religieux dans de nouvelles filières touristiques épurées de leur caractère séculier », par exemple avec des offres entièrement hallal à La Mecque (p. 131).

Lionel Obadia ne se limite pas à exposer les différents types d'analyses économiques de la religion. Il explore aussi les différents liens que peut entretenir la religion avec l'économie. Si la religion «tend à s'aligner sur l'économie»(p.13), inversement, "l'économie prend des accents religieux" (p.13). L'auteur relève en effet que les religions sont de plus en plus nombreuses à faire entendre leur voix pour critiquer l'économie mondiale actuelle, et que parallèlement, les organismes économiques mondiaux, par exemple lors du Forum Mondial de l'Économie à Davos, convient des représentants des religions pour recueillir leur point de vue. Le désenchantement n'est donc pas aussi total qu'on pourrait le penser et des points de jonction entre les deux sphères existent bien.

5 En conclusion, cet ouvrage de Lionel Obadia dresse un riche état des lieux des travaux et problématiques sur la question des liens unissant économie et religions, et plus exactement, concernant l'encore récente économie religieuse. Toutefois, ce tableau presque complet, notamment dans le chapitre sur l'économie des religions, n'aborde que peu la question de l'économie interne des religions non pas limitée à l'échange des biens symboliques mais dans sa dimension fonctionnelle et essentielle pour la subsistance des institutions et des professionnels qui en font partie. Or c'est précisément en étudiant l'économie de subsistance religieuse que l'on vérifie avec plus d'acuité ce que Lionel Obadia observe : «Ce qui est plus intéressant que l'ambivalence des religions, qui sont critiques à l'endroit de la mondialisation, c'est la manière dont elles intègrent les "contre-valeurs" de l'économie de marché dans une rhétorique de l'accommodation de la mondialisation aux religions et non pas le contraire» (p. 119). L'économie des monastères catholiques est un excellent lieu pour observer ces jeux de recompositions en vue d'intégrer l'élément économique à l'utopie religieuse, s'accommodant pour une part des déterminants de l'économie et tâchant pour une autre part de les «traduire » religieusement. Pour finir, relayons cet appel de l'auteur à explorer des champs encore peu étudiés : «Il faudra bien qu'un jour quelqu'un s'attelle à écrire l'histoire de cette économisation de la religion » (p. 104). 